\title{
Laboratory-based surveillance of Pneumocystis jirovecii pneumonia in South Africa, 2006-2010
}

\author{
Desiree du Plessisa, Bhavani Poonsamya, Veerle Msimanga, Leigh Davidsson ${ }^{\mathrm{b} *}$, Cheryl Cohen ${ }^{\mathrm{ac}}$, Nelesh Govenderad, Halima Dawoode, \\ Alan Karstaedt ${ }^{\mathrm{f}}$ and John Frean ${ }^{\text {ad }}$
}

aNational Institute for Communicable Diseases, National Health Laboratory Service, Johannesburg, South Africa

${ }^{b}$ Department of Diagnostics and Vaccinology, Swedish Institute for Communicable Disease Control, Solna, Sweden

'School of Public Health, Faculty of Health Sciences, University of Witwatersrand, Johannesburg, South Africa

${ }^{d}$ School of Pathology, Faculty of Health Sciences, University of Witwatersrand, Johannesburg, South Africa

${ }^{e}$ Department of Medicine, Grey's Hospital; University of KwaZulu-Natal, Pietermaritzburg, South Africa

'Department of Medicine, Chris Hani Baragwanath Hospital, Johannesburg, South Africa

*Corresponding author, email: desireed@nicd.ac.za

\begin{abstract}
Background: We aimed to establish the characteristics of patients with confirmed Pneumocystis jirovecii pneumonia recruited by passive, sentinel laboratory-based surveillance.

Method: The study design was prospective, observational, cross-sectional, laboratory-based sentinel surveillance. Laboratorybased surveillance of Pneumocystis jirovecii pneumonia (PJP), formerly known as Pneumocystis carinii pneumonia (PCP), was conducted in six South African provinces at 61 hospitals, of which 17 were sentinel sites, where surveillance officers collected clinical and demographic data from cases. A case was defined as a patient with a respiratory tract specimen that was confirmed positive for $P$. jirovecii by immunofluorescent microscopy or PCR test, either as a first diagnosis or $\geq 30$ days after the last confirmed laboratory diagnosis of PJP. The chi-square test or Fisher's exact test were used to compare the categorical variables.

Results: From 2006-2010, 1537 cases of PJP were recorded. Eighty-nine per cent (460/518) were found to be human immunodeficiency virus (HIV)-infected. This was a first diagnosis of HIV infection in $57 \%$ of the cases. The case fatality ratio was $34 \%(177 / 525)$. Recurrent infection was significantly more common in the 26- to 45-year age group, compared to children aged $\leq 5$ years (odds ratio 1.7, 95\% confidence interval: 1.1-2.8) ( $p$ 0.040). Treatment for tuberculosis was common in cases aged $\geq 5$ years $(37 \%, 85 / 229)$.

Conclusion: PJP was the acquired immune deficiency syndrome-defining illness in more than half of the patients detected through laboratory-based surveillance. The high mortality rate and number of recurrent cases is noteworthy. This study may not have reflected the full spectrum of clinical presentation of the disease as case report forms were only completed for hospitalised patients at sentinel surveillance sites.
\end{abstract}

Keywords: co-infection, developing countries, HIV infection, opportunistic infection, PJP, Pneumocystis jirovecii, South Africa

\section{Introduction}

Pneumocystis jirovecii is an atypical fungus which causes $P$.jirovecii pneumonia (PJP), formerly known as P. carinii pneumonia (PCP), in immunocompromised individuals, most notably in South Africa in patients with human immunodeficiency virus (HIV) infection. Immunocompetent individuals can be colonised with $P$. jirovecii, while those who are sufficiently immunocompromised may develop clinical PJP.' Before the introduction of highly active antiretroviral therapy in the USA, PJP was the most common opportunistic infection in HIV-infected individuals. ${ }^{2}$

During the first decade of the acquired immune deficiency syndrome (AIDS) pandemic, PJP was rarely recorded in African adults. ${ }^{3}$ This led to the impression that PJP was relatively rare in Africa, and to speculation that Africans might be relatively resistant to PJP. ${ }^{4}$ Studies from African countries have reported variable incidences of PJP in adult patients with HIV/AIDS, and generally higher rates in children..$^{5-9}$ The low prevalence reported in one study was probably owing to under-reporting of the cases. ${ }^{3}$ In addition, tuberculosis and other opportunistic infections may mask the presence of $\mathrm{PJP}^{10}$ and may result in death at an earlier stage of HIV infection than PJP.
Few laboratories offer PJP testing in South Africa. Therefore, most cases are diagnosed clinically and treated empirically. ${ }^{11}$ In 2006, laboratory-based surveillance of PJP began as part of the activities of the Group for Enteric Respiratory and Meningeal Disease Surveillance in South Africa (GERMS-SA) programme. ${ }^{12}$ The aim of this surveillance was to establish the characteristics of patients with laboratory-confirmed PJP throughout South Africa from 2006-2010.

\section{Method}

\section{Study design and population}

Public sector medical laboratories of the National Health Laboratory Service (NHLS) serve an estimated $80 \%$ of the population in South Africa, while services to the remaining $20 \%$ are provided by private laboratories. ${ }^{13}$ Laboratories participating in surveillance performed either microscopy using an immunofluorescent antibody test (IFA) (nine public laboratories), or PCR (one private laboratory group), to diagnose PJP. These laboratories provided PJP tests to 61 hospitals in six of the nine provinces. Trained surveillance officers completed standardised case report forms at 17 of these hospitals, termed sentinel sites, 
by interviewing the patients and/or reviewing the hospital records. The collected data included clinical and demographic information, date of admission, HIV infection status, PJP prophylaxis, discharge diagnosis and in-hospital outcome. HIV infection status was determined during the current admission. Infants aged $\leq 1$ year were tested for HIV by PCR. ${ }^{14}$ Clinical markers of HIV infection were recorded on the case report forms. These included the presence of chronic diarrhoea, oral candidiasis, Kaposi's sarcoma, tuberculosis and HIV wasting syndrome. Audits were conducted annually using the NHLS laboratory information system to detect unreported cases, and these were added to the surveillance database.

\section{Case definition}

A case was defined as a patient with any respiratory tract specimen confirmed positive for the presence of $P$. jirovecii by IFA or PCR test, either as a first diagnosis or $\geq 30$ days after the last laboratory-confirmed PJP diagnosis. Recurrent disease was defined as any patient meeting the above criteria, who had been discharged and readmitted at least one month after the previous episode. Only one case report form and one positive specimen per admission was required for surveillance purposes.

\section{Confirmation of cases}

From May 2006 to December 2010, P. jirovecii-positive specimens were verified by the Parasitology Reference Laboratory, National Institute for Communicable Diseases (NICD). The original specimen (respiratory samples, including expectorated or induced sputum, tracheal aspirate or bronchial washing), or the concentrate used for the IFA test, or the stained or unstained IFA slides, were sent to the NICD. The microscopy results from other testing laboratories were confirmed with a commercial diagnostic kit (Light Diagnostics "' Pneumocystis carinii DFA kit, Millipore, Billerica, USA) using immunofluorescence microscopy. All specimens that were negative by microscopy underwent a quantitative real-time PCR assay for the detection of $P$. jirovecii DNA, as previously described. ${ }^{11}$ In a few cases (129/1 836, 7\%), the positive result from the sending laboratory remained unconfirmed, mainly owing to the nature of the original specimen provided (i.e. an inadequate sample, or only a slide received), but were still included in the analysis.

\section{Statistical analysis}

Continuous variables, such as age, CD4+ T-cell count (adults) or CD4+ T-cell percentage (children) were categorised. For the purposes of this analysis, patients were divided into four age groups: $0-4$ years, $5-25$ years, $26-45$ years and $\geq 45$ years. The CD4+ T-cell count was divided into six categories: 5-50, 51-100, $101-200,201-350,351-500$ and $\geq 500$ cells/ $\mu$ l. The CD4+ T-cell percentage was divided into three groups: $\leq 15,15-24$ and $\geq 25 \%$. The chi-square test or Fisher's exact test were used to compare the categorical variables. Two-tailed $p$-values of $<0.050$ were considered significant. All available case information for each variable was used in univariate analysis. Epidemiological and laboratory data were entered in an Epi Info' database. Analysis was performed using Stata version 10.0.

\section{Ethical approval}

Ethical approval was obtained from the University of the Witwatersrand Human Research Ethics Committee (Medical), and from the ethics committees at participating sites. Interviews were conducted with the informed consent of the patients, their parents or legal guardians. Participants who did not consent to participate in the sentinel surveillance were still included as part of laboratory surveillance as demographic data and specimens were submitted to NICD, for which ethical approval was obtained.

\section{Results}

\section{Surveillance population}

For the study period, 1537 cases of PJP were reported to the NICD. Of these cases, $38 \%(578 / 1537)$ were from the sentinel sites, and of these $91 \%(525 / 578)$ had accompanying available case report forms for analysis. The surveillance audit showed that $98 \%$ (1 806/1 836) of all laboratory-confirmed specimens of PJP were reported through the surveillance system.

\section{Data from national laboratory-based surveillance}

A total of 1836 specimens, from the 1537 cases reported, was submitted. Most specimens were received from Gauteng (49\%) and Western Cape (21\%) provinces. Specimens were also received from Eastern Cape (10\%), North West (7\%), KwaZulu-Natal (5\%), Free State (4\%) and Mpumalanga (3\%) provinces, while less than $1 \%$ of the received specimens were submitted by Limpopo and Northern Cape provinces collectively. Spontaneously expectorated sputum $(77 \%)$ was the most common specimen, collected followed by tracheal aspirate $(11 \%)$. The remainder of samples included bronchoalveolar lavage (6\%), nasopharyngeal aspirate $(1.6 \%)$ and gastric washing (0.1\%).

\section{Age groups and gender of patients}

Age and gender data were collected for $94 \%$ of patients in this study (1 438/1 537). Sixty-two per cent of patients across all the age groups were female. The number and percentage of females per age group were: $0-4$ years, 294 (20\%); 5-25 years, 180 (13\%); $26-45$ years, $823(57 \%)$ and $\geq 45$ years of age, $141(10 \%)$.

Figure 1 illustrates the age and gender distribution among the cases. The highest number of cases occurred in the $\leq 5$-year age group, of whom $97 \%(285 / 294)$ were infants aged $\leq 1$ year, with a median age of 91 days (a range of 2-355 days). Sixty-four per cent of cases (916/1 438) were adults aged 25-44 years. The proportion of female cases was significantly higher in the 5- to 25-year age group [odds ratio (OR) 3.5, 95\% confidence interval (CI): 2.2-5.6) $(p<0.000)$ and 26- to 45-year age group (OR 1.6, $95 \% \mathrm{Cl}: 1.2-2.1)(p=0.002)$, than in the age group of children $\leq 5$ years. There were significantly more males in the $\geq 45$-year age group, than in the $<5$-year age group (OR 0.6 , 95\% Cl: 0.6-0.9) $(p=0.008)$.

\section{Description of patients with confirmed Pneumocystis pneumonia at the sentinel sites}

Case report forms were available for 525 patients diagnosed with PJP. The characteristics of these patients are provided in Table 1. The patient profile for age and gender in cases with case report forms at the sentinel sites was similar to those for the whole cohort, with the exception that there was no statistical significance in the male to female ratio for those aged $\geq 45$ years, compared to those aged $\leq 5$ years.

\section{Clinical diagnosis, case fatality ratios and length of hospital stay}

Most of the patients had a working clinical diagnosis of lower respiratory tract infection (LRTI) $(545 / 577,94 \%)$, followed by tuberculosis $(8 / 577,1 \%)$, bacterial pneumonia $(6 / 577,1 \%)$, PJP $(5 / 577,1 \%)$ and LRTI with diarrhoea $(4 / 577,1 \%)$. The overall case fatality ratio was $34 \%(177 / 525)$, and was significantly higher in the 26- to 45-year age group, compared to children aged $\leq 5$ years $(p$ 0.004). The median length of hospital admission for 


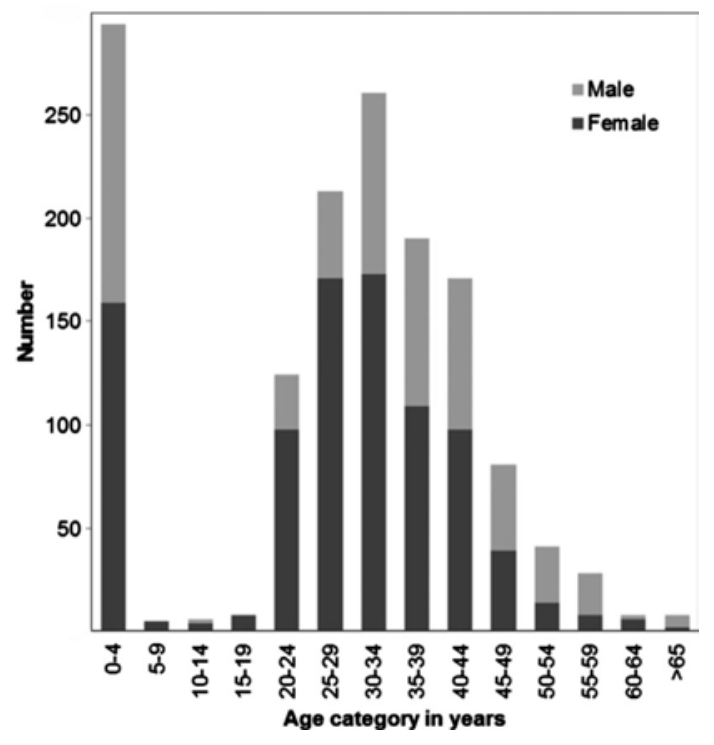

*: Age and gender were not available for $6 \%$ (99/1 537).

Figure 1: Age and gender distribution for patients with laboratoryconfirmed Pneumocystis jirovecii pneumonia reported to the Group for Enteric, Respiratory and Meningeal Disease Surveillance in South Africa programme, South Africa, 2006-2010 $(n=1438)^{39}$

fatal PJP cases was 11 days (a range of $0-95$ days), and 14 days (a range of $0-123$ days) for PJP cases who recovered. A difference in hospital stay was not observed when those who died or survived were compared by HIV infection status.

\section{A comparison of HIV-uninfected and HIV-infected cases}

Fifty-eight of 518 (11\%) patients were HIV uninfected. There were significantly fewer HIV-uninfected persons in cases $\geq 5$ years old $(13 / 290,4 \%)$ compared to those in the $\leq 5$-year age group (45/211, $21 \%)(p<0.000)$. HIV-infected patients $\leq 5$ years experienced significantly higher mortality $(52 / 166,31 \%)$ than HIV-uninfected children $(4 / 45,9 \%)$ in the same age group (OR 4.7, 95\% Cl: $1.5-$ 16.3) $(p=0.004)$. Mortality was not statistically significantly different between cases aged $\geq 5$ years and those aged $\leq 5$ years.
Underlying immunocompromising conditions, other than HIV infection, were recorded in $40 \%$ (18/45) of HIV-uninfected cases, and in 18\% (30/170) of HIV-infected cases, aged $\leq 5$ years (OR 3.1, $95 \% \mathrm{Cl}:$ 1.4-6.8) ( $p=0.001)$. Protein-energy malnutrition, prematurity, immunosuppressive therapy and failure to thrive were the most commonly recorded conditions in HIV-infected cases. Prematurity and immunosuppressive therapy were conditions reported in HIV-uninfected cases. Seventy-seven per cent (10/13) of HIV-uninfected cases aged $\geq 5$ years had underlying immunocompromising conditions, including chronic renal failure and immunosuppressive therapy, compared to $20 \%$ (59/290) of HIV-infected cases, in which lung disease, smoking and alcohol dependency were risk factors (OR 13.1, 95\% Cl: 3.2-61.9) $(p<0.00)$.

\section{HIV-infected cases and recurrent Pneumocystis jirovecii infection}

HIV infection status was available for $518 / 525$ (99\%) cases. The overall prevalence rate was $89 \%(460 / 518)$, and was significantly higher in the 5- to 25-year age group $(p=0.014)$ and 26- to 45year age group $(p<0.000)$ compared to that in children aged $\leq 5$ years. Fifty-seven per cent (254/445) of cases had newlydiagnosed HIV infection on admission. Within the age groups, $80 \%(132 / 166)$ of patients aged $\leq 5$ years, $42 \%(106 / 250)$ of those aged $5-45$ years, and $55 \%(16 / 29)$ of those aged $\geq 45$ years, were newly-diagnosed with HIV infection on admission.

Twenty-five per cent of patients who survived initial hospitalisation had recurrent PJP infection within a year. Recurrent infection was significantly more common in the 26- to 45-year age group, compared to children aged $\leq 5$ years $(p=0.043)$. HIV infection was associated with recurrent PJP infection in children aged $\leq 5$ years $(62 \%, 23 / 37)$ (OR $2.7,95 \% \mathrm{Cl}: 1.0-7.7)(p=0.009)$, but not in the older age groups $(p=0.200)$.

\section{Current antiretroviral treatment}

Thirty-two per cent (170/376) of HIV-infected cases were on current antiretroviral treatment (ART) (Table 1). Children aged $\leq 5$ years were more likely to be on current ART $(104 / 157,66 \%)$ than those in the 5- to 25 -year age group $(8 / 42,19 \%)(p<0.000)$ and 26- to 45 -year age group (50/159, 31\%) $(p<0.001)$. The history of ART and adherence to ART was not recorded.

Table 1: Characteristics of patients with laboratory-confirmed Pneumocystis jirovecii pneumonia by age using sentinel site surveillance in South Africa from $2006-2010(n=525)$

\begin{tabular}{|c|c|c|c|c|c|}
\hline \multirow{3}{*}{$\begin{array}{l}\text { Patient } \\
\text { characteristics }\end{array}$} & \multicolumn{4}{|c|}{ Age group (years) } & \multirow{2}{*}{ Total } \\
\hline & $0-4$ & $5-25$ & $26-45$ & $\geq 45$ & \\
\hline & $\%(\mathrm{n} / \mathrm{N})$ & $\begin{array}{c}\% \text { (n/N)OR }(95 \% \mathrm{Cl}) \\
\text { (p-value) }\end{array}$ & $\begin{array}{c}\% \text { (n/N)OR }(95 \% \mathrm{Cl}) \\
\text { (p-value) }\end{array}$ & $\begin{array}{c}\% \text { (n/N)OR }(95 \% \mathrm{Cl}) \\
\text { (p-value) }\end{array}$ & $\%(\mathrm{n} / \mathrm{N})$ \\
\hline Female & $\begin{array}{c}55(107 / 196) \\
\text { Reference }(\leq 5 \text {-year age } \\
\text { group) }\end{array}$ & $\begin{array}{c}82(40 / 49) 3.7(1.7-8.0)(p \\
=0.001)^{*}\end{array}$ & $\begin{array}{c}74(170 / 230) 2.3(1.5-3.5) \\
(p<0.000)^{*}\end{array}$ & $\begin{array}{c}41(11 / 27) \\
0.6(0.3-1.3)\end{array}$ & $65(328 / 502)$ \\
\hline Case fatality ratio & $\begin{array}{c}27(59 / 220) \\
\text { Reference }(\leq 5 \text {-year age } \\
\text { group) }\end{array}$ & $29(14 / 48) 1.1(0.5-2.4)$ & $\begin{array}{c}40(92 / 231) 1.8(1.2-2.7) \\
(p=0.004)^{*}\end{array}$ & $\begin{array}{c}46(12 / 26) \\
2.3(1.0-5.8)\end{array}$ & $34(177 / 525)$ \\
\hline HIV infected & $\begin{array}{c}79(170 / 215) \\
\text { Reference }(\leq 5 \text {-year age } \\
\text { group) }\end{array}$ & $\begin{array}{c}94(46 / 49) 4.1(1.1-15.3) \\
(p=0.014)^{*}\end{array}$ & $\begin{array}{c}98(224 / 228) 14.8 \\
(5.0-42.5)(p<0.000)^{*}\end{array}$ & $\begin{array}{c}77(20 / 26) \\
0.9(0.3-2.7)\end{array}$ & $89(460 / 518)$ \\
\hline Recurrent infection & $\begin{array}{l}20 \text { (38/191)Reference } \\
\text { ( } \leq 5 \text {-year age group) }\end{array}$ & $29(9 / 31) 1.7(0.6-4.1)$ & $\begin{array}{c}30(46 / 154) 1.7(1.0-2.9) \\
(p=0.043)^{*}\end{array}$ & $\begin{array}{c}39(7 / 18) \\
2.6(0.8-7.8)\end{array}$ & $25(100 / 394)$ \\
\hline Currently on ART & $\begin{array}{c}66(104 / 157) \text { Reference } \\
\text { ( } \leq 5 \text {-year age group) }\end{array}$ & $\begin{array}{c}19(8 / 42) 0.12(0.05-0.29) \\
(p<0.000)^{*}\end{array}$ & $\begin{array}{c}31(50 / 159) 0.23(0.14- \\
0.38)(p<0.001)^{*}\end{array}$ & $\begin{array}{c}44(8 / 18) \\
0.41(0.14-1.20)\end{array}$ & $45(170 / 376)$ \\
\hline
\end{tabular}

Note: ART: antiretroviral therapy, HIV: human immunodeficiency virus

*:Statistically significant difference compared with $\leq 5$-year age group (reference) 
The case fatality ratio for children aged $\leq 5$ years was significantly lower in patients on current ART. Eighty-two per cent (80/98) of these children survived, compared to $66 \%(61 / 93)$ of untreated children (OR 2.3, 95\% Cl: 1.1-5.0) ( $p=0.001)$. There was no significant association between mortality and ART in the other age groups.

\section{CD4+ T-lymphocyte count, Pneumocystis jirovecii prophylaxis and treatment}

The CD4+ T-lymphocyte count was available for $69 \%$ (247/358) of HIV-infected cases aged $\geq 5$ years. Most cases $(240 / 247,97 \%)$ had a CD4+ T-lymphocyte count $\leq 200$ cells $/ \mathrm{mm}^{3}$, and of these, $80 \%$ $(193 / 240)$ had a CD4+ T-cell count that was $\leq 50$ cells $/ \mathrm{mm}^{3}$. CD4+ T-cell percentage data were available for $72 \%$ of HIV-infected children aged $\leq 5$ years (123/170). Half of these children (61/123) were severely immunosuppressed $(\leq 15 \%), 26 \%(32 / 123)$ had evidence of moderate suppression (15-24\%), while $24 \%$ (30/123) of the children had little evidence of suppression ( $\geq 25 \%$ ).

Thirty-five per cent (121/346) of cases had started cotrimoxazole at least one week prior to admission. In-hospital treatment information was available for 500 cases. Eighty-two per cent $(408 / 500)$ received cotrimoxazole during their current admission. Six cases received only dapsone, and 10 cases both cotrimoxazole and dapsone. Twelve cases were reported to not have received any treatment for PJP, although they tested positive using IFA. Of these cases, two died in hospital, and five of the remainder received a concomitant diagnosis of tuberculosis.

\section{HIV marker diseases and co-infections}

The majority of children aged $\leq 5$ years $(127 / 165,77 \%)$ and $94 \%$ $(216 / 229)$ of cases aged $\geq 5$ years had a clinical sign of HIV infection other than PJP. The most common HIV marker was oral candidiasis $(26 \%, 43 / 165)$, followed by tuberculosis $(5 \%, 8 / 165)$, in children aged $\leq 5$ years. The most common HIV markers in children aged $\geq 5$ years were wasting (45\%, 104/229), followed by oral candidiasis $(42 \%, 96 / 229)$ and tuberculosis $(37 \%, 85 / 229)$.

\section{Discussion}

It was found in this study using national laboratory-based surveillance for PJP that most cases occurred in infants aged $\leq 1$ year and in adults aged 26-45 years. More than a third of patients had a concurrent infection with oral candidiasis and/or pulmonary tuberculosis.

Spontaneously expectorated sputum was most commonly received for PJP testing, and although not the preferred sample type for testing, it was previously shown to be sensitive enough to identify PJP in HIV-infected patients. ${ }^{15}$ The higher number of cases reported from Gauteng and Western Cape provinces may be due to the clustering of academic hospitals attached to testing laboratories in those areas. It may also be a result of specimen-taking practices which vary between the different academic institutions of the country, rather than a higher prevalence of PJP in these provinces.

The high number of cases of PJP in children aged $\leq 5$ years underscored the results of previous studies which showed that PJP is a common AIDS-defining infection in infants in South Africa. ${ }^{6}$ Our study demonstrated that adults aged $25-44$ years had the highest prevalence of PJP in the adult age groups, with significantly more females affected than males. HIV prevalence has been found to be higher in adult females than males in all age groups in South Africa, ${ }^{16}$ and this is the probable reason for our finding.
Mixed infections with various pathogens are common in both adult and paediatric patients, ${ }^{17}$ and this may be the reason why LRTI was the most common clinical diagnosis at discharge. The aetiology of acute bacterial or viral infections was frequently not sought or recorded. The diagnosis of PJP in some cases may not have been known before discharge. The data showed that PJP was a strong indicator of HIV infection in the absence of other immunocompromising conditions. PJP is an opportunistic infection, most often diagnosed in HIV-infected individuals. ${ }^{2}$ Therefore, a high prevalence of PJP was expected, reflecting South Africa's high HIV prevalence rate. ${ }^{16}$ Because of the limitations of this passive surveillance system, we were unable to determine the general population prevalence of PJP, although the high number of patients in our series in whom PJP was an AIDS-defining infection suggests that it is substantial. The prevalence of PJP in HIV-infected children with acute respiratory disease in Africa has been shown to be more than $40 \%,{ }^{17-19}$ mostly in infants aged $\leq 6$ months, ${ }^{18,20,21}$ and PJP signals rapid progression to AIDS and death..$^{22}$ Our study confirmed this as HIV-infected children aged $\leq 5$ years were more likely to die than HIV-uninfected children. A high number of patients were readmitted to hospital for recurrent PJP. Only patients who sought medical care in the same area as the previous episode could be identified as having a recurrent infection. Thus, the rate of recurrent infection may well be higher than that suggested in this study. HIV infection was significantly associated with recurrent PJP infection in children aged $\leq 5$ years, but not in the older age groups. Just over a third of cases started cotrimoxazole prophylaxis at least one week prior to admission, and $82 \%$ of cases received cotrimoxazole on discharge. Whether this high recurrence of PJP cases was due to inadequate treatment, failure of prophylaxis for PJP, or failure of adherence to the medication, is unknown.

Significantly higher case fatality ratios were recorded in HIVinfected children aged $\leq 5$ years than in those who were HIV uninfected, but the provision of ART in HIV-infected children was associated with lower case fatality rates. The mortality rate pertaining to our patients was higher than in the developed world. This may be because of the more rapid progression of HIV infection in developing countries, and the high number of coinfections in individuals. ${ }^{23-25} \mathrm{~A}$ significant difference in mortality was not shown between patients aged $\geq 5$ years who were, or were not, on ART. PJP was the AIDS-defining illness on admission for more than half of the cases, suggesting delayed presentation to the hospital and corresponding late diagnosis. Therefore, many patients may have only recently started ART. There is a significant risk of developing an opportunistic infection during the initial months of starting $A R T, 26,27$ and patients who start it when their CD4+ T-cell count is $\leq 200$ cells $/ \mathrm{mm}^{3}$ are at a higher risk of clinical progression to AIDS and death. ${ }^{28}$ Starting ART under such circumstances may also lead to a worse PJP outcome, due to immune reconstitution syndrome..$^{29}$ The immune response contributes to lung damage with PJP infection, and for this reason, HIV-uninfected patients and those on current ART whose CD4+ T-cell count increases, tend to fare generally worse than those patients who are unable to generate an immune response. ${ }^{30}$

Unlike the case in older children and adults, CD4+ T-cell count is not a good indicator of risk for PJP in infants aged $\leq 1$ year. Many young infants with PJP have a CD4+ T-cell count of $\geq 1500$ cells/ $\mathrm{mm}^{3}$, and the count can drop very rapidly shortly before PJP develops in infants. ${ }^{31}$ Two thirds of HIV-infected children aged $\leq 5$ years were shown to be immunodeficient according to their 
CD4+ percentage, irrespective of their HIV infection status. HIVexposed infants born to HIV-infected mothers have lower CD4+ T-lymphocyte count which persists over time, ${ }^{32}$ making them more susceptible to acquiring pathogenic organisms from their immunodeficient mothers. ${ }^{33}$

The failure of prophylaxis occurred in $32 \%$ of children aged $\leq$ 5 years, and in $38 \%$ of adults and children aged $\geq 5$ years old. Similar high rates of prophylaxis failure have been found in other studies. A significant difference in the risk of contracting PJP was not found between infants hospitalised with severe pneumonia who received adequate cotrimoxazole prophylaxis, and those who did not, in a study at Chris Hani Baragwanath Hospital in Soweto. ${ }^{17}$ However, there was an association between infants who received prophylaxis for PJP and a better outcome. Similarly, a study performed in Zambia reported a better outcome for PJP in children on prophylaxis. ${ }^{34}$ The same applied to HIV-infected African adults who were on cotrimoxazole prophylaxis. ${ }^{35}$

Most of the HIV-negative patients in all the age groups had an underlying immunocompromising condition which could predispose them to PJP. These findings are in agreement with those in a study from Spain. ${ }^{36}$

\section{Study limitations}

The main aim of this surveillance programme was to describe the characteristics of patients with laboratory-confirmed PJP throughout South Africa from 2006-2010. There were inherent limitations to the surveillance system. Limited numbers of PJP tests were requested by clinicians, few specimens were obtained by induced sputum or bronchoalveolar lavage for patients without spontaneous sputum production, testing sites were limited to laboratories attached to large academic centres, and data from the surveillance system were not as suitable as population-based surveillance for the epidemiological monitoring of PJP in our target population. As resources for testing are limited, clinicians often treat empirically, basing PJP diagnosis on $\mathrm{X}$-rays and clinical evaluation. ${ }^{37}$ Surveillance through this laboratory-based surveillance network identified approximately 270 cases of PJP per year. This number is much lower than that for other opportunistic infections under surveillance. ${ }^{38,39}$ Patients who were tested for PJP may not reflect the full spectrum of clinical PJP presentations, and results may be biased towards hospitalised patients.

Despite these limitations, laboratory-based surveillance provided us with insight into the characteristics of patients with PJP in South Africa. The high mortality rate and number of recurrent cases of PJP is worrying and requires further investigation. This study has laid the groundwork for further research on the prevalence and impact of PJP in South Africa. We initiated a syndromic surveillance programme for PJP which enrolls patients who are hospitalised for severe acute respiratory infections.

Acknowledgements - The authors gratefully acknowledge their laboratory and clinical colleagues who participated in the GERMS-SA surveillance programme from 2006-2010, including:

- Sandeep Vasaikar, Vivek Bhat and Kamal Baba (Eastern Cape).

- Peter Smith, Andre Moller, Anne-Marie Pretorius and Eugene Elliot (Free State).

- Pyu-Pyu Sein, Anwar Hoosen, Ruth Lekalakala, Donald Ngwira, Olga Perovic, Charles Feldman, Alan Karstaedt, Mike Dove, Kathy Lindeque, Linda Meyer, Jeannette Wadula, David Moore, Trusha
Nana, Maphoshane Nchabeleng, Norma Bosman and Bonnie Maloba (Gauteng).

- Wim Sturm, Prathna Bhola, Prashini Moodley, Sharona Seetharam, Sindisiwe Sithole, Halima Dawood, Sumayya Haffajee, Yacoob Coovadia, Nomonde Dlamini, Prasha Mahabeer and Yesho Mahabeer (KwaZulu-Natal).

- Ken Hamese (Limpopo).

- Greta Hoyland and Jacob Lebudi (Mpumalanga).

- Stan Harvey and Pieter Jooste (Northern Cape).

- Danie Cilliers and Andrew Rampe (North West).

- Andrew Whitelaw, Rena Hoffman, Elizabeth Wasserman, Siseko Martin and Preneshni Naicker (Western Cape).

- Adrian Brink, Inge Zietsman, Suzy Budavari, Xoliswa Poswa, Maria Botha and Mark Cruz da Silva (Ampath).

- Claire Heney, Kureshnee Pillay, Jaunita Smit, Chetna Govind and Ben Prinsloo (Lancet).

- Marthinus Senekal and Jennifer Coetzee (Pathcare).

- Anne Schuchat, Stephanie Schrag, Chris van Beneden, Elizabeth Zell, Tom Chiller, Fred Angulo, Nancy RosenteinMessonier, Katherine Robinson and Angela Ahlquist (CDC).

- Victor Fernandez (SMI, Sweden) and Michelle Wong (Chris Hani Baragwanath Hospital).

- Keith Klugman, Anne von Gottberg, Linda de Gouveia, Karen Keddy, Arvinda Sooka, Vanessa Quan, Kerrigan McCarthy, Susan Gould, Elizabeth Prentice, Susan Meiring, Mireille Cheyip, Jeffrey Ramalivhana, Penny Crowther, Jay Patel, Deliwe Nkosi, Melony Fortuin-de Smidt, Taskeen Khan, Claire von Mollendorf, Marshagne Smith and Jabulani Ncayiyana (NICD).

Funding - GERMS-SA is financially supported by the NICD/ NHLS, and in part through a cooperative agreement with the CDC (U2G/PS001328)

Conflict of interest - Nelesh Govender has received honoraria from MSD and Pfizer for speaking engagements, has received a research grant from Pfizer South Africa for an unrelated surveillance project, and is a consultant for Fujifilm Pharmaceuticals. Halima Dawood has received honoraria for speaking engagements from Novartis South Africa and MSD South Africa and a travel grant from Novartis South Africa.

Declaration - This manuscript was supported financially by NICD/ NHLS and the President's Emergency Plan for AIDS Relief through the Centers for Disease Control and Prevention (CDC) under the terms of 5U2GPS001328. Its contents are solely the responsibility of the authors, and do not necessarily represent the official views of the NICD, NHLS or the CDC.

\section{Note}

i Part of this data was presented at the $16^{\text {th }}$ International Congress on Infectious Diseases, Cape Town, from 2-5 April 2014.

\section{References}

1. Maskell NA, Waine DJ, Lindley A., et al. Asymptomatic carriage of Pneumocystis jiroveci in subjects undergoing bronchoscopy: a prospective study. Thorax. 2003;58(7):594-7.

2. Lu JJ, Lee CH. Pneumocystis pneumonia. J Formos Med Assoc. 2008;107(11):830-42

3. Morris A, Lundgren JD, Masur $\mathrm{H}$, et al. Current epidemiology of Pneumocystis pneumonia. Emerg Infect Dis. 2004;10(10):1713-20.

4. Ansari NA, Kombe $\mathrm{AH}$, Kenyon TA, et al. Pathology and causes of death in a group of 128 predominantly HIV-positive patients in Botswana, 1997-1998. Int J Tuberc Lung Dis. 2002;6(1):55-63. 
5. van Oosterhout JJ, Laufer MK, Perez MA, et al. Pneumocystis pneumonia in HIV-positive Adults, Malawi. Emerg Infect Dis. 2007;13(2):325-8.

6. Zar HJ, Dechaboon A, Hanslo D, et al. Pneumocystis carinii pneumonia in South African children infected with human immunodeficiency virus. Pediatr Infect Dis J. 2000;19(7):603-7.

7. Aderaye G, Bruchfeld J, Aseffa G, et al. Pneumocystis jiroveci pneumonia and other pulmonary infections in TB smear-negative HIV-positive patients with atypical chest X-ray in Ethiopia. Scand J Infect Dis. 2007;39(11-12):1045-53.

8. Chakaya JM, Bii C, Ng'ang'a L, et al. Pneumocystis carinii pneumonia in HIV/AIDS patients at an urban district hospital in Kenya. East Afr Med J. 2003;80(1):30-5.

9. Mahomed AG, Murray J, Klempman S, et al. Pneumocystis carinii pneumonia in HIV infected patients from South Africa. East Afr Med J 1999;76(2):80-4.

10. Aderaye G, Bruchfeld J, Olsson M, et al. Occurrence of Pneumocystis carinii in HIV-positive patients with suspected pulmonary tuberculosis in Ethiopia. AIDS. 2003;17(3):435-40.

11. Dini L, du Plessis M, Frean J, et al. High prevalence of dihydropteroate synthase mutations in Pneumocystis jirovecii isolated from patients with Pneumocystis pneumonia in South Africa. J Clin Microbiol. 2010;48(6):2016-21.

12. Govender N, Quan V, Prentice E, et al. GERMS-SA: a national South African surveillance network for bacterial and fungal diseases. Communicable Diseases Surveillance Bulletin. Johannesburg: National Institute for Communicable Diseases of the National Health Laboratory Service; 2006 May. Available from: http://www.nic.ac.za/ assets/files/CommDisBullMay06.pdf.

13. NHLS - About Us. National Health Laboratory Service of South Africa. 2012. Available from: http://www.nhls.ac.za/about.us.

14. Burgard $M$, Blanche $S$, Jasseron $C$, et al. Performance of HIV-1 DNA or HIV-1 RNA tests for early diagnosis of perinatal HIV-1 infection during anti-retroviral prophylaxis. J Pediatr. 2012;160(1):60-66.e1.

15. Metersky ML, Aslenzadeh J, Stelmach P. A comparison of induced and expectorated sputum for the diagnosis of Pneumocystis carinii pneumonia. CHEST J. 1998;113(6):1555-9.

16. UNAIDS Global report on the AIDS epidemic 2010. Geneva: UNAIDS; 2010. Available from: http://www.unaids.org/globalreport.

17. Madhi SA, Cutland C, Ismail K, et al. Ineffectiveness of trimethoprimsulfamethoxazole prophylaxis and the importance of bacterial and viral coinfections in african children with Pneumocystis carinii pneumonia. Clin Infect Dis. 2002;35(9):1120-6.

18. Chintu C, Mudenda V, Lucas S, et al. Lung diseases at necropsy in African children dying from respiratory illnesses: a descriptive necropsy study. Lancet. 2002;360(9338):985-90.

19. Graham SM, Mtitimila El, Kamanga HS, et al. Clinical presentation and outcome of Pneumocystis carinii pneumonia in Malawian children. Lancet. 2000;355(9201):369-73.

20. Ikeogu MO, Wolf B, Mathe S. Pulmonary manifestations in HIV seropositivity and malnutrition in Zimbabwe. Arch Dis Child. 1997;76(2):124-8.

21. Graham SM, Gibb DM. HIV disease and respiratory infection in children. Br Med Bull. 2002;61:133-50.

22. Gibb DM, Davison CF, Holland FJ, et al. Pneumocystis carinii pneumonia in vertically acquired HIV infection in the British Isles. Arch Dis Child. 1994;70(3):241-4.

23. Fisk DT, Meshnick S, Kazanjian PH. Pneumocystis carinii pneumonia in patients in the developing world who have acquired immunodeficiency syndrome. Clin Infect Dis. 2003;36(1):70-8.
24. Preidis GA, McCollum ED, Mwansambo C, et al. Pneumonia and malnutrition are highly predictive of mortality among African children hospitalized with human immunodeficiency virus infection or exposure in the era of antiretroviral therapy. J Pediatr. 2011;159(3):484-9.

25. Wang HW, Lin CC, Kuo CF, et al. Mortality predictors of Pneumocystis jirovecii pneumonia in human immunodeficiency virus-infected patients at presentation: experience in a tertiary care hospital of northern Taiwan. J Microbiol Immunol Infect. 2011;44(4):274-81.

26. Ledergerber B, Egger $M$, Erard $V$, et al. AIDS-related opportunistic illnesses occurring after initiation of potent antiretroviral therapy. JAMA. 1999;282(23):2220-6.

27. Manosuthi W, Chaovavanich A, Tansuphaswadikul S, et al. Incidence and risk factors of major opportunistic infections after initiation of antiretroviral therapy among advanced HIV-infected patients in a resource-limited setting. J Infect. 2007;55(5):464-9.

28. Egger M, May M, Chêne G, et al. Prognosis of HIV-1-infected patients starting highly active antiretroviral therapy: a collaborative analysis of prospective studies. Lancet. 2002;360(9327):119-29.

29. Wislez M, Bergot $E$, Antoine $M$, et al. Acute respiratory failure following HAART introduction in patients treated for Pneumocystis carinii pneumonia. Am J Respir Crit Care Med. 2001;164(5):847-51.

30. Huang L, Morris A, Limper AH, et al. An official ATS workshop summary: recent advances and future directions in Pneumocystis pneumonia (PCP). Proc Am Thorac Soc. 2006;3(8):655-64.

31. Simonds RJ, Lindegren ML, Thomas $P$, et al. Prophylaxis against Pneumocystis carinii pneumonia among children with perinatally acquired human immunodeficiency virus infection in the United States. N Engl J Med. 1995;332(12):786-90.

32. Nielsen SD, Jeppesen DL, Kolte $L$, et al. Impaired progenitor cell function in HIV-negative infants of HIV-positive mothers results in decreased thymic output and low CD4 counts. Blood. 2001;98(2):398404.

33. McNally LM, Jeena PM, Gajee K, et al. Effect of age, polymicrobial disease, and maternal HIV status on treatment response and cause of severe pneumonia in South African children: a prospective descriptive study. Lancet. 2007;369(9571):1440-51.

34. Chintu C, Bhat GJ, Walker AS, et al. Co-trimoxazole as prophylaxis against opportunistic infections in HIV-infected Zambian children (CHAP): a double-blind randomised placebo-controlled trial. Lancet. 2004;364(9448):1865-71.

35. Badri M, Ehrlich R, Wood R, et al. Initiating co-trimoxazole prophylaxis in HIV-infected patients in Africa: an evaluation of the provisional WHO/UNAIDS recommendations. AIDS. 2001;15(9):1143-8.

36. Calderón EJ, Varela JM, Medrano FJ, et al. Epidemiology of Pneumocystis carinii pneumonia in southern Spain. Clin Microbiol Infect. 2004;10(7):673-6.

37. Harris JR, Marston BJ, Sangrujee N, et al. Cost-effectiveness analysis of diagnostic options for Pneumocystis pneumonia (PCP). PLoS ONE. 2011;6(8):e23158.

38. Meiring ST, Quan VC, Cohen C, et al. A comparison of cases of paediatric-onset and adult-onset cryptococcosis detected through population-based surveillance, 2005-2007. AIDS. 2012 Nov 28;26(18):2307-14.

39. Group for Enteric, Respiratory and Meningeal disease Surveillance in South Africa. GERMS-SA Annual Report 2011. National Institute for Communicable Diseases; 2011. Available from: http://www.nicd. ac.za/assets/files/2011\%20GERMS-SA\%20Annual\%20report\%20 Final.pdf. 